Int. J. Electrochem. Sci., 14 (2019) 3217 - 3228

International Journal of

ELECTROCHEMICAL

SCIENCE

WWW.electrochemsci.org

\title{
Formation of Fe-Sn intermetallic layer and its effect on the corrosion of 304 stainless steel in high temperature water
}

\author{
Jian-jun Guan ${ }^{1}$, Hong-yuan Zhong ${ }^{1}$, Li Feng ${ }^{2}$,Yan Zhao ${ }^{\text {* }}$, Feng Liu ${ }^{1}$, Ping Liang ${ }^{1}$, \\ Cong-qian Cheng ${ }^{3}$, Jie Zhao ${ }^{3}$ \\ ${ }^{1}$ School of Mechanical Engineering, Liaoning Shihua University, Fushun 113001, Liaoning, China \\ ${ }^{2}$ School of Electrical Engineering, Shengyang Polytechnic College, Shenyang 110045, China \\ ${ }^{3}$ School of Materials Science and Engineering, Dalian University of Technology, Dalian 116085, \\ Liaoning, China \\ *E-mail: zhaoyan-a@,163.com
}

doi: $10.20964 / 2019.04 .15$

Received: 2 December 2018 / Accepted: 6 February 2019 / Published: 10 March 2019

Fe-Sn compound layer on interface was studied during the interaction between liquid Sn and 304 stainless steel (304 SS), and the effect of the intermetallics on the corrosion of $304 \mathrm{SS}$ in $300{ }^{\circ} \mathrm{C}$ high temperature water was researched. The experimental results indicate that a $(\mathrm{Fe}, \mathrm{Cr}) \mathrm{Sn}_{2}$ compound layer forms at the $\mathrm{Sn} / 304 \mathrm{SS}$ interface. The average thickness of the layer is in proportion to square root of reaction time, indicating a diffusion control process for the intermetallics growth. After corrosion in 300 ${ }^{\circ} \mathrm{C}$ water, the ( $\left.\mathrm{Fe}, \mathrm{Cr}\right) \mathrm{Sn}_{2}$ layer changes surface oxide film composition from hematite $\mathrm{Fe}_{2} \mathrm{O}_{3}$ and spinel $\mathrm{Fe}_{3} \mathrm{O}_{4}$ to $\mathrm{SnO}_{2}$ and spinel $\mathrm{Fe}_{3} \mathrm{O}_{4}$. Microcracks and spallation tendency in the oxide films is due to the FeSn intermetallics attachment. From the potentiodynamic polarization, the oxide film that formed on stainless steel with Fe-Sn intermetallics attachment significantly deteriorated the corrosion resistance compared with that the samples without intermetallics attachment.

Keywords: Sn, Stainless steel; Intermetallics, liquid-solid reactions, Oxidation, High temperature water

\section{$\underline{\text { FULL TEXT }}$}

(C) 2019 The Authors. Published by ESG (www.electrochemsci.org). This article is an open access article distributed under the terms and conditions of the Creative Commons Attribution license (http://creativecommons.org/licenses/by/4.0/). 